\title{
Autoradiographic Changes in Central Benzodiazepine Binding Sites and Their Coupling to $\gamma$-Aminobutyric Acid Receptors after Seizures in the Developing Rat
}

\author{
MARIE-CHRISTINE WERCK AND JEAN-LUC DAVAL
}

INSERM U.272, 54013 Nancy, France

\begin{abstract}
Benzodiazepines are psychoactive substances classically used for their anticonvulsant properties in neonates as well as in adults. In a previous work, we have shown that seizures lead to an age-dependent upregulation of central benzodiazepine binding sites measured in isolated rat cerebral membranes. However, information concerning regional changes in the receptor density was lacking. In our present study, the effects of bicucullineinduced seizures were investigated by quantitative autoradiography of central benzodiazepine receptors in developing rats and in adults. Animals were killed $30 \mathrm{~min}$ after an intraperitoneal injection of either saline or a convulsive dose of bicuculline. Benzodiazepine binding sites in brain sections were labeled by $\left[{ }^{3} \mathrm{H}\right]$ flunitrazepam. Generalized seizures induced a widespread increase in benzodiazepine receptors, with a marked enhancement in structures that mediate seizure activity, such as substantia nigra, amygdala, septum, and hippocampus. The addition of exogenous $\gamma$-aminobutyric acid to the incubation medium increased benzodiazepine binding by the same order of magnitude whether rats were given saline or bicuculline, suggesting that additional benzodiazepine sites are also functionally linked to $\gamma$-aminobutyric acid receptors. The age-related postictal increase in benzodiazepine receptors might reflect a compensatory response for protection against recurrent seizures, especially in newborns. (Pediatr Res 30: 100105, 1991)
\end{abstract}

\section{Abbreviations}

GABA, $\gamma$-aminobutyric acid

Numerous neuropathologic studies have pointed out that during the neonatal period and early infancy, epileptic manifestations are relatively frequent, with peculiar characteristics. Children are more susceptible to epileptic brain damage than adults (1), and recurrent or prolonged seizures in infants and children may be followed by major neurologic sequelae (2).

Benzodiazepines are psychoactive drugs with anxiolytic, anticonvulsant, and muscle relaxant properties that are widely prescribed in neonates as well as in adults (3). The mechanism of benzodiazepine central action has been attributed to a highaffinity, saturable, and specific binding site and its interaction with a GABA-regulated chloride channel $(4,5)$. In animals,

Received October 16, 1990; accepted February 6, 1991.

Correspondence: Dr. Jean-Luc Daval, INSERM U.272, 24-30 rue Lionnois, B.P. 3069,54013 NANCY Cédex, France.

Supported by the Institut National de la Santé et de la Recherche Médicale and by a grant from the Fondation pour la Recherche Médicale. benzodiazepines are able to antagonize a wide variety of chemically induced seizures, including those produced by pentylenetetrazol, bicuculline, picrotoxin, or strychnine (6).

Using cerebral membrane preparations, rapid increases in the number of brain benzodiazepine receptors after seizures induced by pentylenetetrazol $(7,8)$ or electroshock $(8)$ have been described in the adult rat. Furthermore, in a previous work, we have shown that bicuculline-induced seizures lead to an agedependent up-regulation of central benzodiazepine binding sites (9). Thirty min after their induction, generalized seizures increased the total number of specific brain benzodiazepine recognition sites without changes in receptor affinity (9). However, no information was available concerning regional changes in the receptor density.

In our present study, the effects of bicuculline-induced seizures were investigated by quantitative autoradiography of central benzodiazepine receptors (labeled by $\left[{ }^{3} \mathrm{H}\right]$ flunitrazepam) in developing rats and in adults. Because it has been shown that GABA receptor agonists may enhance benzodiazepine specific binding (10), the functional coupling of benzodiazepine binding sites with GABA receptors was studied by examining the effects of exogenous GABA on flunitrazepam specific binding.

\section{MATERIALS AND METHODS}

Animals. Sprague-Dawley female rats were housed together with males for $4 \mathrm{~d}$. They were then separated during their pregnancy and lactation period. After delivery, each litter was reduced to 10 pups for homogeneity, and animals were constantly maintained under standard laboratory conditions on a $12: 12 \mathrm{~h}$ light/dark cycle (lights on at $0600 \mathrm{~h}$ ) with food and water available ad libitum. Animals were used at four developmental stages $(5,15$, and $25 \mathrm{~d}$ after birth and the adult stage). Developing animals of both sexes and male adults only were included in the study. Animal experimentation reported in our study was performed according to highest standards of animal care.

Pharmacologic treatment. Experimental seizures were induced in rats (six per group) by an acute intraperitoneal administration of bicuculline (Fluka AG, Buchs, Switzerland). Bicuculline was dissolved in physiologic saline in the presence of $40 \mu \mathrm{L} 1 \mathrm{M} \mathrm{HCl}$ and the final solution was adjusted at about $\mathrm{pH} 7$ with $1 \mathrm{M}$ $\mathrm{NaOH}$. Bicuculline solutions were prepared to inject the convulsant agent in a constant volume of $2.5 \mu \mathrm{L} / \mathrm{g}$ body weight and doses were chosen to elicit generalized seizures at each developmental stage. Adults (60-70 d) and 25-d-old rats were given bicuculline at a dose of $4 \mathrm{mg} / \mathrm{kg}$. At $15 \mathrm{~d}$ of age, animals received the drug at a dose of $2 \mathrm{mg} / \mathrm{kg}$, whereas 5 -d-old pups received 0.8 $\mathrm{mg}$ bicuculline per $\mathrm{kg}$. Seizures could be observed within $1 \mathrm{~min}$ after the drug administration, and their duration was similar in all animals. Control rats (six per group) were given intraperitoneally an equivalent volume of saline. 
Slice preparation. Animals were killed by decapitation $30 \mathrm{~min}$ after the drug (or saline) injection. The brains were rapidly removed, frozen in isopentane previously chilled to $-30^{\circ} \mathrm{C}$, and stored in plastic bags at $-80^{\circ} \mathrm{C}$ until sectioned. After being coated with cold embedding medium (carboxymethyl cellulose $4 \%$ in water), the brains were cut into $16-\mu \mathrm{m}$ coronal sections at $-20^{\circ} \mathrm{C}$ in a cryostat. Tissue sections obtained at various brain levels were thaw-mounted onto gelatin-coated glass slides (two per slide) and stored at $-80^{\circ} \mathrm{C}$ until assayed. Adjacent sections were fixed and stained with thionin for anatomical identification according to the rat brain atlas of Paxinos and Watson (11) for the adult animals and according to the developing rat brain atlas of Sherwood and Timiras (12) for all other stages.

Receptor binding assay. Central type benzodiazepine binding sites were analyzed using $\left[{ }^{3} \mathrm{H}\right]$ flunitrazepam as previously described by Schlumpf et al. (13). The assay was carried out by incubating the brain sections for $40 \mathrm{~min}$ at $4^{\circ} \mathrm{C}$ in $50 \mathrm{mM}$ Tris$\mathrm{HCl}$ buffer (pH 7.4) containing $100 \mathrm{mM} \mathrm{NaCl}$ and $1 \mathrm{nM}\left[{ }^{3} \mathrm{H}\right]$ flunitrazepam $(2.85 \mathrm{TBq} / \mathrm{mmol}$; Commissariat à l'Energie Atomique, Saclay, France). The slides were then rinsed twice for 1 min in buffer, dipped in cold water, and finally air-dried.

Nonspecific binding was measured by adding $1 \mu \mathrm{M}$ clonazepam (kindly provided by Roche S.A., Neuilly-sur-Seine, France) and was estimated between 0 and $5 \%$ of total binding.

The coupling of benzodiazepine binding sites with GABA receptors was tested on adjacent sections using the same procedure with addition of $10^{-4} \mathrm{M} \mathrm{GABA}$ to the incubation medium (10).

Quantitative analysis. Dried sections were exposed to LKB Ultrofilm along with tritium standards $\left(\left[{ }^{3} \mathrm{H}\right]\right.$ microscales; Amersham, Arlington Heights, IL) previously calibrated according to Geary and Wooten (14). The films were exposed for $2 \mathrm{wk}$ for all developmental stages studied. The autoradiographs were analyzed for quantitative densitometry with a computerized image processing system (Biocom 200, Les Ulis, France). For each cerebral structure, OD measurements were made bilaterally in two to four brain sections and finally converted into fmol $\left.{ }^{3} \mathrm{H}\right]$ ligand bound per mg tissue equivalent, according to the calibration curve obtained from the calibrated standards.

Statistical analysis. Flunitrazepam binding was measured in 46 structures in two groups (bicuculline and saline) of six animals at four different developmental stages. Specific binding values in the bicuculline group were compared with those in the saline group by a nonpaired $t$ test. Furthermore, changes in the receptor binding after seizures in developing animals were statistically compared with those obtained in adult animals by means of a one-way analysis of variance followed by a Dunett's test for multiple comparison. For each brain structure examined, the effects of exogenous GABA on flunitrazepam specific binding were tested by comparing flunitrazepam binding in the presence or in the absence of $10^{-4} \mathrm{M}$ GABA with a paired $t$ test, and the data were compared between bicuculline- and saline-treated animals using a nonpaired $t$ test.

\section{RESULTS}

Distribution of flunitrazepam binding sites. The distribution of $\left[{ }^{3} \mathrm{H}\right]$ flunitrazepam specific binding in the 5-d-old rat brain was in good correlation with that observed in the adult animal, which exhibited the characteristic pattern of central benzodiazepine binding site distribution. The recognition sites were particularly concentrated in the molecular layer of the cerebellum, the superior colliculi, the substantia nigra reticulata, the mamillary bodies, the amygdala, and the hippocampal formation, as well as the cerebral cortices (Fig. 1). Ontogenetically, a progressive increase in the receptor density was observed from $5 \mathrm{~d}$ of age to the adult stage.

Effect of seizures on ${ }^{3}$ H]flunitrazepam specific binding. At each stage of postnatal development studied, experimental seizures induced a widespread increase in $\left[{ }^{3} \mathrm{H}\right]$ flunitrazepam spe- cific binding in the rat brain. However, the magnitude of changes in flunitrazepam binding after bicuculline-induced seizures differed according to the cerebral structure examined. Therefore, the present report will focus on those brain structures that exhibited the most representative changes.

Figure 2 illustrates changes in $\left[{ }^{3} \mathrm{H}\right]$ flunitrazepam specific binding observed in cerebral cortices. The average increase in flunitrazepam binding was about $40 \%$ in developing animals, whereas it was about $20 \%$ in adults, with maximum changes observed in motor cortex.

In the motor system (Fig. 3), $\left[{ }^{3} \mathrm{H}\right]$ flunitrazepam binding was significantly enhanced in bicuculline-treated developing rats in all structures examined, with high changes in the substantia nigra reticulata. Increases in benzodiazepine specific binding were found to be lower in adult animals as compared to animals at other stages, with no significant change in caudate nuclei (Fig. $3)$.

Within the limbic system, medial habenula was the only structure that did not exhibit significant increases in $\left[{ }^{3} \mathrm{H}\right]$ flunitrazepam specific binding (Fig. 4). Conversely, enhanced binding properties could be seen in all limbic areas analyzed, with differences in values between developing and adult rats being especially noticeable in the laterodorsal part of septum and in the amygdala. Among the different hippocampal layers, marked increases in flunitrazepam binding were observed after generalized seizures in strata oriens and radiatum in both $\mathrm{CA}_{1}$ and $\mathrm{CA}_{3}$ subfields (Fig. 5). Smaller changes were measured in the lacunosum molecular layer as well as in the dentate gyrus. Again, increases in flunitrazepam specific binding were significantly higher in developing than in mature animals in numerous structures.

In summary, Figures 3-5 show that, at 5 and $15 \mathrm{~d}$ of age, 20 out of the 22 cerebral structures presently reported exhibited a highly significant $(p<0.01)$ increase in $\left[{ }^{3} \mathrm{H}\right]$ flunitrazepam specific binding $30 \mathrm{~min}$ after the induction of seizures. The bicuculline-induced stimulation of flunitrazepam binding was significantly higher than in adult animals in 12 and 14 structures at 5 and $15 \mathrm{~d}$ of age, respectively. In 25-d-old rats, seizures translated into a significant increase in flunitrazepam binding in 21 brain structures, whereas enhancement of the benzodiazepine binding was significantly higher than in adult animals in 10 areas. Finally, in adult brains, $\left[{ }^{3} \mathrm{H}\right]$ flunitrazepam specific binding was significantly increased in bicuculline- versus saline-treated animals in 19 structures.

Influence of exogenous $G A B A$. In control animals, in vitro addition of $10^{-4} \mathrm{M}$ GABA to the incubation medium induced a significant increase in $\left.{ }^{3} \mathrm{H}\right]$ flunitrazepam specific binding in all structures at all developmental stages studied. The GABA-related stimulation of flunitrazepam binding appeared to be age-dependent, because the average increases were $61.1 \pm 9.2 \%$ at $5 \mathrm{~d}$ of age, $45.3 \pm 8.9 \%$ at $15 \mathrm{~d}, 26.8 \pm 7.8 \%$ at $25 \mathrm{~d}$, and $22.6 \pm 7.7 \%$ at the adult stage.

After bicuculline-induced seizures, exogenous GABA enhanced flunitrazepam binding in every brain area by the same order of magnitude as in saline-treated animals. Specific flunitrazepam binding increased by $60.9 \pm 11.0 \%$ at $5 \mathrm{~d}, 44.1 \pm 9.6 \%$ at $15 \mathrm{~d}, 28.8 \pm 6.1 \%$ at $25 \mathrm{~d}$, and $22.7 \pm 7.6 \%$ in adult rats.

\section{DISCUSSION}

Our study provides new insights into regional changes in central benzodiazepine binding sites after generalized seizures. Bicuculline-induced seizures lead to a widespread increase in benzodiazepine receptors with a marked enhancement in brain structures that mediate seizure activity. Receptor changes are age-dependent and data suggest that increased flunitrazepam specific binding sites are linked to GABA receptors.

Choice of the convulsant. Information processing in the brain depends on the dynamic interactions of excitatory and inhibitory systems. GABA is a major inhibitory neurotransmitter substance and it has been shown that impaired GABAergic transmission 

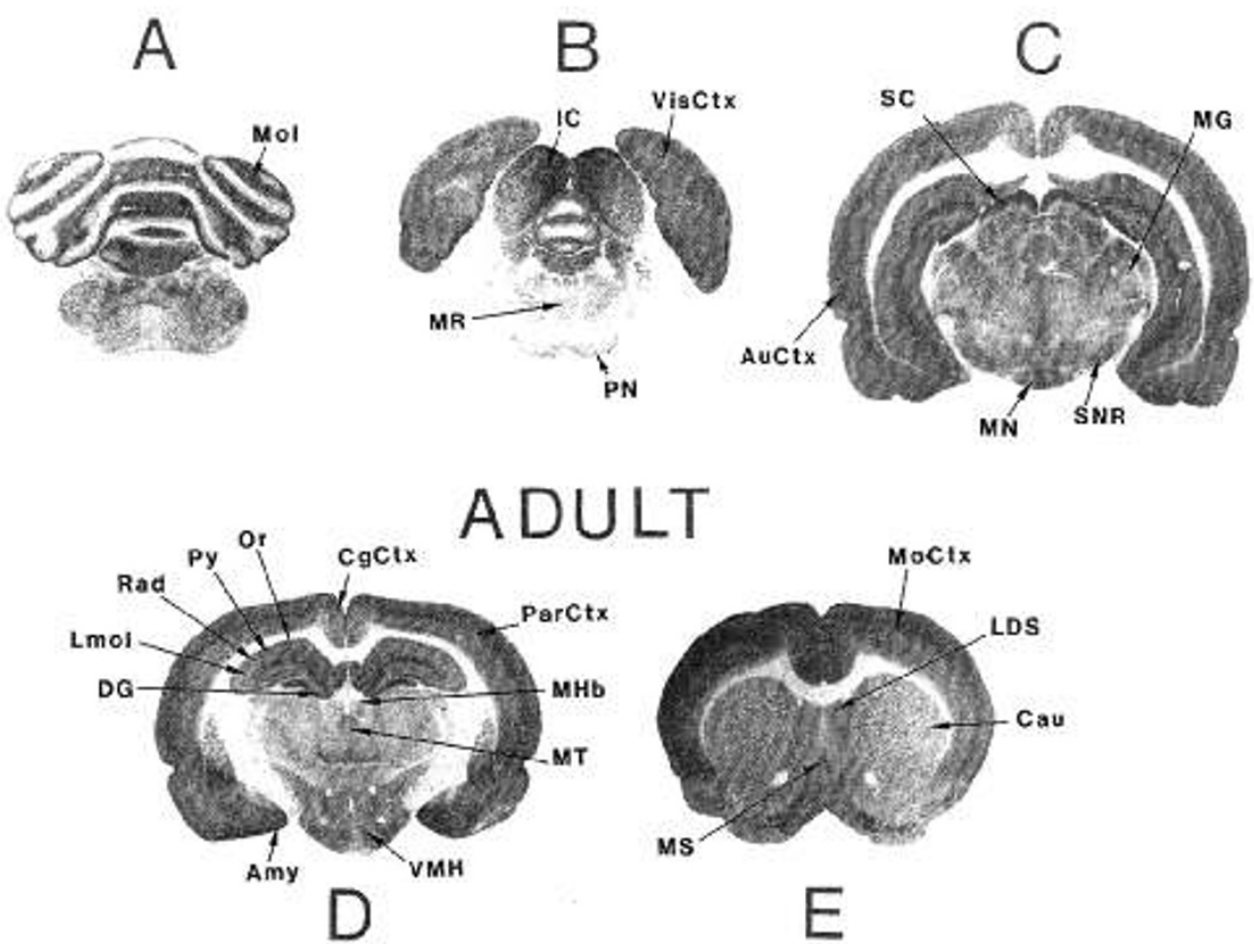

Fig. 1. Autoradiographic distribution of $\left[{ }^{3} \mathrm{H}\right]$ flunitrazepam binding sites in representative coronal sections at various levels of adult control rat brain. Slide-mounted cerebral sections in the plane of cerebellum $(A)$, raphe nuclei $(B)$, substantia nigra $(C)$, anterior hippocampus $(D)$, and striatum $(E)$ were incubated as described in Materials and Methods with $1 \mathrm{nM}\left[{ }^{3} \mathrm{H}\right]$ flunitrazepam in the presence or absence of $10^{-4} \mathrm{M}$ GABA. Brain sections were coexposed with calibrated $\left[{ }^{3} \mathrm{H}\right]$ standards to LKB-Ultrofilm, and autoradiographs were quantitatively analyzed by a computer image-processing system. Nonspecific binding was not above film background. $M o l$, molecular layer of cerebellum; VisCtx, visual cortex; $I C$, inferior colliculus; $M R$, medial raphe, PN, pontine nuclei; SC, superior colliculus; $A u C t x$, auditory cortex; $M N$, mammillary nuclei; $S N R$, substantia nigra reticulata; $M G$, medial geniculate nucleus; $C g C t x$, cingulate cortex; $O r$, stratum oriens; $P y$, pyramidal cell layer; Rad, stratum radiatum; Lmol, lacunosum molecular layer; $D G$, dentate gyrus; $A m y$, amygdala; $V M H$, ventromedial hypothalamus; $M T$, medial thalamus; MHb, medial habenula; ParCtx, parietal cortex; $M o C t x$, motor cortex; $M S$, medial septum; $L D S$, laterodorsal septum; Cau, caudate nucleus.

MOTOR CTX

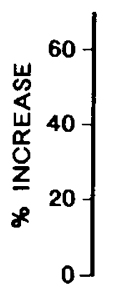

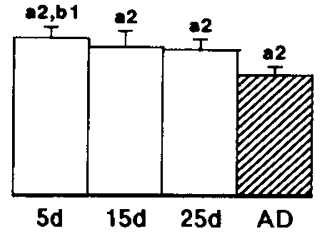

5d 15d 25d AD
VISUAL CTX

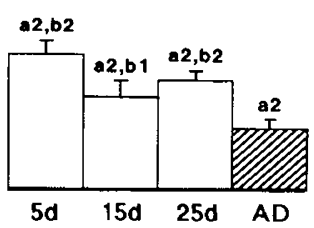

AUDITORY CTX

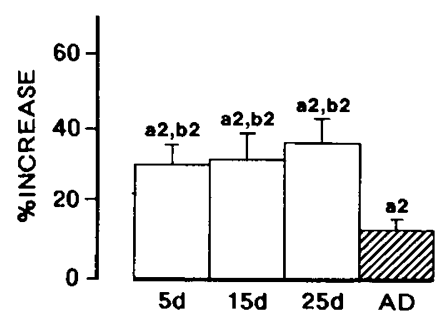

CINGULATE CTX

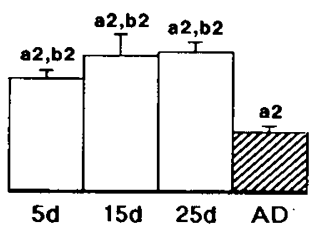

PARIETAL CTX

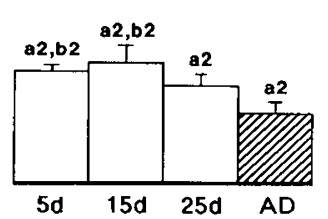

Fig. 2. Effects of bicuculline-induced seizures on $\left[{ }^{3} \mathrm{H}\right]$ flunitrazepam specific binding in cerebral cortices of rats at various developmental stages. Data are expressed as mean percentage of increase $( \pm$ SEM $)$ as compared to saline-treated control rats. Statistically significant differences from control are denoted by $a l(p<0.05)$ or $a 2(p<0.01)(t$ test). Statistically significant changes in flunitrazepam binding between developing and adult brain structures are denoted by $b 1(p<0.05)$ or $b 2(p<0.01)$ (Dunett's test for multiple comparison). 
CAUDATE NUCL.
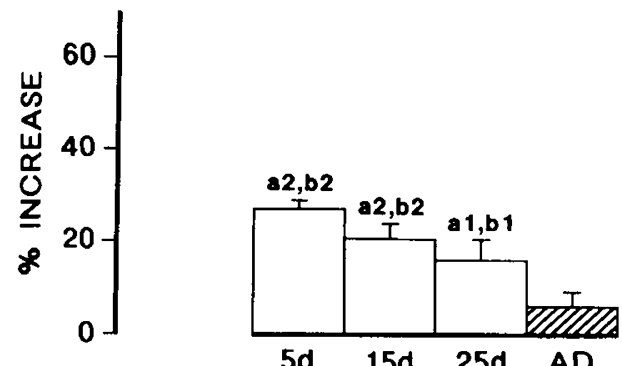

SUBST. NIGRA(RET)

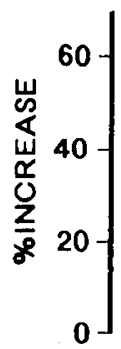

MEDIAL THAL.

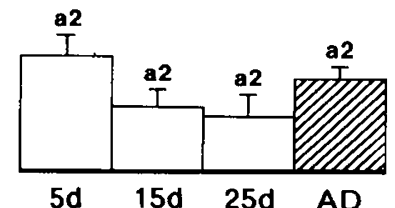

\section{CEREBEL.(MOL. LAYER)}

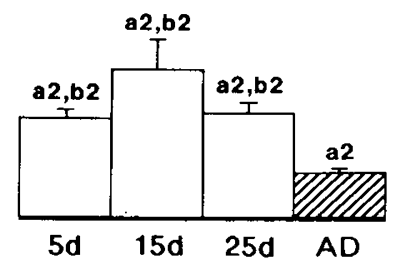

Fig. 3. Effects of bicuculline-induced seizures on $\left[{ }^{3} \mathrm{H}\right]$ flunitrazepam specific binding in motor areas of rats at various developmental stages. Data are expressed as mean percentage of increase $( \pm$ SEM) as compared to saline-treated control rats. Statistically significant differences from control are denoted by al $(p<0.05)$ or $a 2(p<0.01)(t$ test). Statistically significant changes in flunitrazepam binding between developing and adult brain structures are denoted by $b 1(p<0.05)$ or $b 2(p<0.01)$ (Dunett's test for multiple comparison). THAL, thalamus; RET, reticulata.

LAT. DORS. SEPTUM

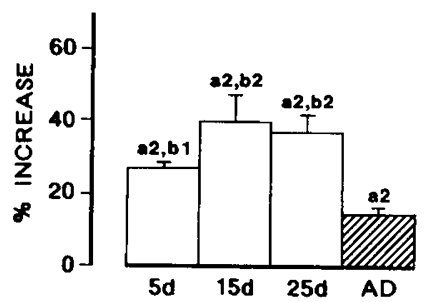

AMYGDALA

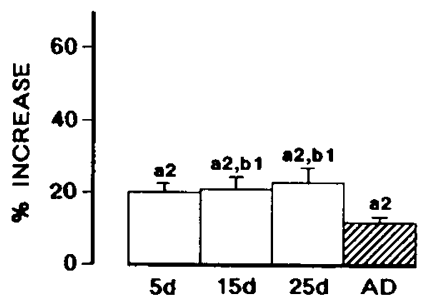

MEDIAL SEPTUM

MEDIAL HABEN.
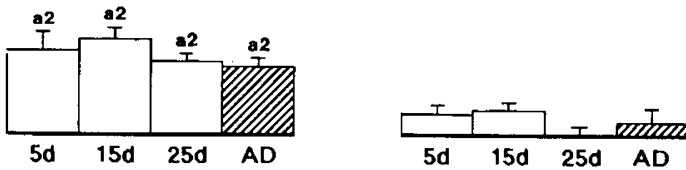

MAMMILLARY NUCL.

VENTROMED HYPOTH.
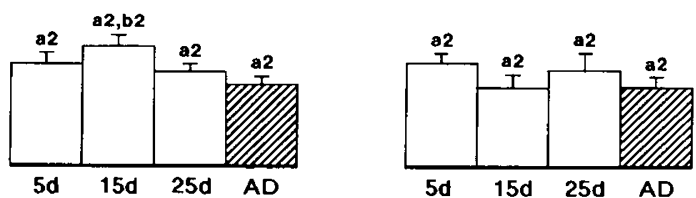

Fig. 4. Effects of bicuculline-induced seizures on $\left.{ }^{3} \mathrm{H}\right] \mathrm{flunitrazepam} \mathrm{specific} \mathrm{binding} \mathrm{in} \mathrm{limbic} \mathrm{areas} \mathrm{of} \mathrm{rats} \mathrm{at} \mathrm{various} \mathrm{developmental} \mathrm{stages.} \mathrm{Data}$ are expressed as mean percentage of increase $( \pm \mathrm{SEM})$ as compared to saline-treated control rats. Statistically significant differences from control are denoted by al $(p<0.05)$ or $a 2(p<0.01)(t$ test). Statistically significant changes in flunitrazepam binding between developing and adult brain structures are denoted by $b 1(p<0.05)$ or $b 2(p<0.01)$ (Dunett's test for multiple comparison). HABEN, habenula; HYPOTH, hypothalamus.

plays a critical role in the ethio-pathology of seizures (15). Bicuculline is a specific antagonist of GABA receptors (16). The bicuculline model of seizures was extensively studied and data outlined general features of seizure activity in immature $(17,18)$ as well as in adult rats $(19,20)$. In developing rats, bicuculline induces epileptic manifestations that correlate well with those observed in convulsive disorders in infants and children $(1,17)$.

Development of central benzodiazepine receptors. Benzodiazepines are appropriate drugs for anticonvulsant therapy because they increase the affinity of GABA for its $\mathrm{GABA}_{\mathrm{A}}$-subtype recep- 

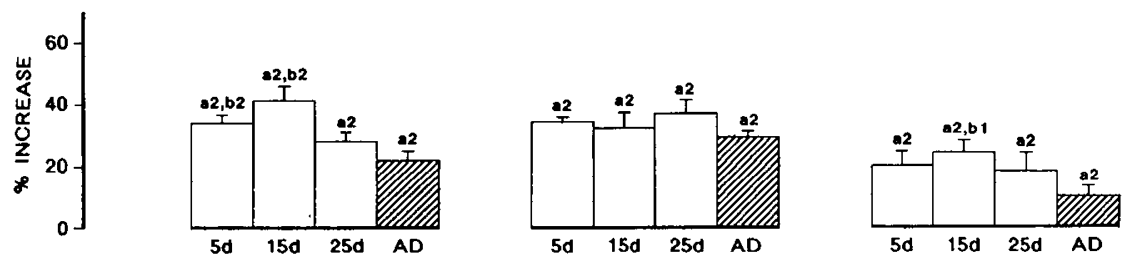

CA3 ORIENS

CA3 RADIATUM

MOLECULAR DG

GRANULAR DG
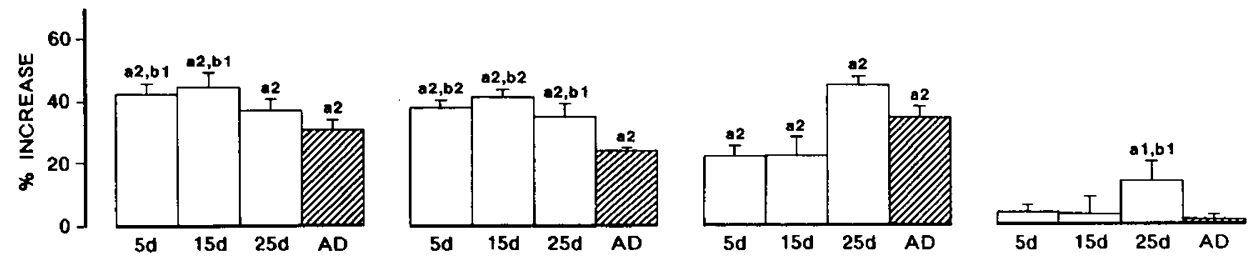

Fig. 5. Effects of bicuculline-induced seizures on $\left[{ }^{3} \mathrm{H}\right]$ flunitrazepam specific binding in different layers of the hippocampus of rats at various developmental stages. Data are expressed as mean percentage of increase $( \pm$ SEM) as compared to saline-treated control rats. Statistically significant differences from control are denoted by $a 1$ ( $p<0.05)$ or $a 2(p<0.01)(t$ test). Statistically significant changes in flunitrazepam binding between developing and adult brain structures are denoted by $b 1(p<0.05)$ or $b 2(p<0.01)$ (Dunett's test for multiple comparison). $D G$, dentate gyrus.

tor. They are presumed to act against seizures by enhancing GABA-related synaptic inhibition via an interaction with their specific central binding sites.

In the rat brain, benzodiazepine binding sites are detectable as early as the 14th d after conception (13). At birth, these receptors are present at a relatively high density and they reach adult levels about 3 wk later. During postnatal development, the increase in benzodiazepine binding has been demonstrated to be due to a larger number of specific sites, rather than to a higher receptor affinity (21-23). A sequential development of benzodiazepine receptors in relation to the time course of maturation of cerebral structures could be shown, with a proliferation peak that parallels rapid brain growth in the rat (between 5 and $15 \mathrm{~d}$ of age). Furthermore, a functional relationship with GABA receptors has been observed as soon as birth in all brain structures (24).

Seizure-induced changes in benzodiazepine receptors. The upregulation of central benzodiazepine binding sites observed in our study after experimentally induced seizures is consistent with previous studies performed with cerebral membrane preparations (7-9). Thirty min after seizure induction, $\left[{ }^{3} \mathrm{H}\right]$ flunitrazepam specific binding is significantly augmented in numerous brain areas. Close examination of the data suggests that generalized bicuculline seizures do not translate into random increase in benzodiazepine binding, but rather into organized up-regulation of receptors in selective and predictable anatomical sites, in relationship with seizure development and maintenance. Cerebral cortex exhibits high stimulation of flunitrazepam binding, correlating with the involvement of cortical mechanisms in seizures, even in very young animals. The most important changes in benzodiazepine receptor density can be observed in the substantia nigra, an area rich in benzodiazepine and GABA receptors, which plays an essential role in the generation of paroxysmal activity $(25,26)$. The marked augmentation in flunitrazepam specific binding in limbic structures, including septum, amygdala, and mammillary nuclei, as well as most regions of the hippocampus, parallels the functional anatomy of limbic seizures (27) and probably reflects the limbic component in bicucullineinduced seizures in young animals as well. Moreover, high local changes in brain benzodiazepine binding after seizures strikingly correlate with local cerebral changes in energy metabolism and protein synthesis in bicuculline models of seizures in rats $(20$, $28)$ and newborn monkeys $(29,30)$.

One of the most salient features in our study is the agedependent properties of the effect of seizures on benzodiazepine central recognition sites. Indeed, although the sex composition was different between adult and developing rats, $\left[{ }^{3} \mathrm{H}\right]$ flunitrazepam specific binding commonly increases more sharply in developing animals than in adult animals in almost all of the structures examined, particularly in those involved in convulsions. Such a phenomenon has been previously reported on whole brain isolated membranes (9) and could reflect the high sensitivity of the immature brain.

Benzodiazepine receptor coupling to GABAergic system. Evidence has been provided that GABA enhances benzodiazepine specific binding by increasing the apparent affinity of the receptor for benzodiazepines (10). Using cerebral membrane preparations or autoradiographic procedure, it has been shown that in vitro addition of GABA induces an age-dependent stimulation of benzodiazepine binding in all brain regions $(23,24,31)$. These data have been confirmed in the present study, inasmuch as in control animals the GABA-related increase in flunitrazepam binding was higher at $5 \mathrm{~d}$ of age (around $60 \%$ ) than at the adult stage (around $20 \%$ ). Interestingly, although $\left[{ }^{3} \mathrm{H}\right]$ flunitrazepam specific binding was significantly increased after generalized seizures, addition of $10^{-4} \mathrm{M}$ GABA to the incubation medium increased flunitrazepam specific binding by the same order of magnitude in the bicuculline-treated animals as in the salinetreated ones. Such observations strongly suggest that seizureinduced additional brain benzodiazepine binding sites are also linked to GABA receptors and, as a consequence, are functional.

Receptor plasticity and physiologic implications. The phenomenon of plasticity of neuronal receptors has been extensively studied. After seizures, changes in several central receptors have been described, including noradrenaline (32), dopamine (33), Nmethyl-D-aspartate (34), and adenosine (9) receptors, as well as central benzodiazepine recognition sites $(7-9,35,36$, the present study). These changes appear to be directly related to seizures themselves, inasmuch as Ito et al. (37) have shown that subconvulsive doses of bicuculline do not induce any changes in benzodiazepine binding. Similarly, repeated administration of electrical current without generating seizures does not cause an increase in benzodiazepine receptors (36). At the present time, it is not clear whether the hypoxic component of seizures is involved in the up-regulation of benzodiazepine binding sites. Indeed, McNamara et al. (36) have reported that hypoxic episodes do not affect diazepam binding in rat hippocampal tissue, whereas Ninomiya et al. (38) have shown that the numbers of both GABA and benzodiazepine binding sites are increased 
significantly in the rat brain after a 6-h exposure to hypoxia. The increase in benzodiazepine binding site density is probably not the reflection of de novo protein synthesis, inasmuch as changes are detectable within 15-30 min after the beginning of seizures. One alternative explanation might be that seizures are associated with changes in the binding properties of some endogenous ligand(s) for benzodiazepine sites.

In conclusion, our investigation has demonstrated a significant increase in central benzodiazepine specific binding after seizures, especially in cerebral structures known to participate in the generation or in the propagation of seizure activity. An increased number of receptors in the CNS is believed to be associated with a higher or more sensitive physiologic response (39). Taken together, our data support the hypothesis that seizure-induced increase in functional benzodiazepine receptor number may be a compensatory response to epileptiform activity that contributes to lower seizure susceptibility during the postical period, especially in very young children.

Acknowledgments. The authors thank Professor Paul Vert, director of INSERM U.272, for his encouragement and advice and V. Koziel for her help in the manuscript illustration.

\section{REFERENCES}

1. Aicardi J, Chevrie JJ 1970 Convulsive status epilepticus in infants and children A study of 239 cases. Epilepsia 11:187-197

2. Chevrie JJ, Aicardi J 1978 Convulsive disorders in the first year of life: neurological and mental outcome and mortality. Epilepsia 19:67-74

3. Tallman JF, Paul SM, Skolnick P, Gallager DW 1980 Receptors for the age of anxiety: pharmacology of the benzodiazepines. Science 207:274-281

4. Möhler H, Okada T 1977 Benzodiazepine receptor: demonstration in the central nervous system. Science 198;849-851

5. Squires R, Braestrup C 1977 Benzodiazepine receptors in rat brain. Nature 266:732-734

6. Costa E, Guidotti A, Mao C, Suria A 1975 New concepts on the mechanism of action of benzodiazepines. Life Sci 17:167-186

7. Paul SM, Skolnick P 1978 Rapid changes in brain benzodiazepine receptors after experimental seizures. Science 202:892-894

8. Mimaki T, Yabuuchi H, Laird H, Yamamura HI 1984 Effects of seizures and antiepileptic drugs on benzodiazepine receptors in rat brain. Pediatr Pharmacol 4:205-211

9. Daval JL, Sarfati A 1987 Effects of bicuculline-induced seizures on benzodiazepine and adenosine receptors in developing rat brain. Life Sci 41:16851693

10. Tallman JF, Thomas JW, Gallager DW 1978 GABAergic modulation of benzodiazepine binding site sensitivity. Nature 274:383-385

11. Paxinos G, Watson C 1982 The Rat Brain in Stereotaxic Coordinates. Academic Press, New York

12. Sherwood NM, Timiras PS 1970 A Stereotaxic Atlas of the Developing Rat Brain. University of California Press, Berkeley

13. Schlumpf M, Richards JG, Lichtensteiger W, Möhler H 1983 An autoradiographic study of the prenatal development of benzodiazepine-binding sites in rat brain. J Neurosci 3:1478-1487

14. Geary WA, Wooten GF 1983 Quantitative film autoradiography of opiate agonist and antagonist binding in rat brain. J Pharmacol Exp Ther 23:234240

15. Meldrum BS 1975 Epilepsy and $\gamma$-aminobutyric acid-mediated inhibition. Int Rev Neurobiol 17:1-36

16. Johnston GA, Beart PM, Curtis DR, Game CJ, McCulloch RM, Maclachan
RM 1972 Bicuculline methochloride as a GABA antagonist. Nature 240:219-220

17. De Feo MR, Mecarelli O, Ricci GF 1985 Bicuculline- and allylglycine-induced epilepsy in developing rats. Exp Neurol 90:411-421

18. Zouhar A, Mares P, Liskova-Bernaskova K, Mudrochova M 1989 Motor and electrographic epileptic activity induced by bicuculline in developing rats. Epilepsia 30:501-510

19. Meldrum BS, Nilsson B 1976 Cerebral blood flow and metabolic rate early and late in prolonged epileptic seizures induced in rats by bicuculline. Brain 99:523-542

20. Ingvar M, Siesjö BK 1983 Local blood flow and glucose consumption in the rat brain during sustained bicuculline induced seizures. Acta Neurol Scand 68:129-144

21. Braestrup C, Nielsen M 1978 Ontogenetic development of benzodiazepine receptors in the rat brain. Brain Res 147:170-173

22. Candy JM, Martin IL 1979 The postnatal development of the benzodiazepine receptor in the cerebral cortex and cerebellum of the rat. J Neurochem 32:655-658

23. Aldinio C, Balzano MA, Savoini G, Leon A, Toffano G 1981 Ontogeny of ${ }^{3} \mathrm{H}$ diazepam binding sites in different rat brain area. Dev Neurosci 4:461-466

24. Daval JL, Werck MC, Nehlig A, Pereira de Vasconcelos A 1991 Quantitative autoradiographic study of the postnatal development of benzodiazepine binding sites and their coupling to GABA receptors in the rat brain. Int $J$ Dev Neurosci (in press)

25. Gale K 1985 Mechanisms of seizure control mediated by $\gamma$-aminobutyric acid: role of the substantia nigra. Fed Proc 44:2414-2424

26. Morimoto K, Goddard GV 1987 The substantia nigra is an important site for the containment of seizure generalization in the kindling model of epilepsy. Epilepsia 28:1-10

27. Collins RC, Tearse RG, Lothman EW 1983 Functional anatomy of limbic seizures: focal discharges from medial enthorinal cortex in rat. Brain Res 208:25-40

28. Ben-Ari Y, Tremblay E, Riche D, Ghilini G, Naquet R 1981 Electrographic clinical and pathological alterations following systemic administration of kainic acid, bicuculline or pentetrazole: metabolic mapping using the deoxyglucose method with special reference to the pathology of epilepsy. Neuroscience 6:1361-1391

29. Dwyer BE, Fujikawa DG, Wasterlain CG 1986 Metabolic anatomy of generalized bicuculline seizures in the newborn marmoset monkey. Exp Neurol 94:213-227

30. Dwyer BE, Wasterlain CG 1984 Selective focal inhibition of brain protein synthesis during generalized bicuculline seizures in newborn marmoset monkeys. Brain Res 308:109-121

31. Mallorga P, Hamburg M, Tallman JF, Gallager DW 1980 Ontogenetic changes in GABA modulation of brain benzodiazepine binding. Neuropharmacology 19:405-408

32. Chen MJ, Vigil A, Savage DD, Weiss GK 1990 Transient elevation of amygdala $\alpha 2$ adrenergic receptor binding sites during the early stages of amygdala kindling. Epilepsy Res 5:85-91

33. Fochtmann LJ, Cruciani R, Aiso M, Potter WZ 1989 Chronic electroconvulsive shock increases D1 receptor binding in rat substantia nigra. Eur J Pharmacol 167:305-306

34. Yeh GC, Bonhaus DW, Nadler JV, McNamara JO 1989 N-methyl-D-aspartate receptor plasticity in kindling: quantitative and qualitative alterations in the N-methyl-D-aspartate receptor-channel complex. Proc Natl Acad Sci USA 86:8157-8160

35. Tietz EI, Gomez F, Berman RF 1985 Amygdala kindled seizure stage is related to altered benzodiazepine binding site density. Life Sci 36:183-190

36. McNamara JO, Peper AM, Patrone V 1980 Repeated seizures induced longterm increase in hippocampal benzodiazepine receptor. Proc Natl Acad Sci USA 77:3029-3032

37. Ito Y, Lim DK, Hoskins B, Ho IK 1988 Bucuculline upregulation of GABA receptors in rat brain. $\mathrm{J}$ Neurochem $51: 145-152$

38. Ninomiya H, Taniguchi T, Kameyama M, Fujiwara M 1988 Increased bindin of $\left[{ }^{3} \mathrm{H}\right]$ muscimol and $\left[{ }^{3} \mathrm{H}\right]$ flunitrazepam in the rat brain under hypoxia. $J$ Neurochem 51:1111-1117

39. Burt DR, Creese I, Snyder SH 1977 Anti-schizophrenic drugs: chronic treatment elevates dopamine receptor binding in brain. Science 196:326-328 